\title{
La Carta de Privilegios de Alhama de Granada
}

Agnosco veteris vestigia.

Era corriente en nuestra Patria y desde la Edad Media, la concesión por ilos Monarcas de Cartas de Privilegios a personas, clases y poblaciones determinadas. Unas veces, tales Cartas eran otorgadas graciosamente por los Reyes, en pago a los méritos o servicios recibidos, o que se esperaban recibir de los beneficiarios; otras eran pactadas, o sea, fruto de un acuerdo, que, generalmente, se tramitaba más o menos laboriosamente, en forma de propuesta por los futuros agraciados y aceptación por el Monarca; y otras, en fin, revestían caracteres de impuestas, siendo hijas de revueltas o violencias, ejercidas en la persona del Soberano que las autorizaba.

Llegóse a abusar mucho de ellas, habiéndolas en gran número contra ley y contra fuero, por lo que, para aminorar en lo posible los conflictos a que daban lugar, en las famosas Leyes de Partidas —en el título dieciocho de la Partida tercera- se intentó regularlas, empezando por definir así: "privilegio tanto quiere decir como ley que es dada $\mathbf{u}$ otorgada del Rey y apartadamente a algun lugar o algun ome, para facerle bien e merced" y continuando con normas para evitar las contrarias al derecho natural, la fe y la justicia; aunque en verdad, no debieron servir de mucho esos preceptos, pues la realidad demostraba que, sobre todo por voluntad real, tales privilegios seguían en boga y en su más variada gama. 
La Carta que nos ocupa pertenece a la categoría de las otorgadas o concedidas; aquí la magnanimidad real se ejercita como premio a la ciudad de Alhama, por su comportamiento en la lucha contra los moros y para más alentarle en la misma. Fué dada por los Reyes Católicos (1474-1517) en fecha 22 de marzo de 1484, en tiempo de D. Iñigo López de Mendoza, Conde de Tendilla (título creado en 1465) y Capitán general de la expresada ciudad.

Dicho Conde, oriundo de Guadalajara, después de la conquista de Alhama a los moros en el año 1482, quedó al frente del ejército de su guarnición, para defenderla de sus ataques, como ciudad, entonces, fronteriza a ellos; en ocasión de faltarle numerario para pagar a sus soldados, les entregó unos vales equivalentes a las cantidades adeudadas, con los cuales se efectuaron transacciones en curso forzoso y constituyendo así el primer antecedente en España del papel moneda, que hasta muy posteriormente, en 1780 , no tiene carácter oficial y general.

Su estructura es la de un libro, rudimentariamente encuadernado en terciopelo rojo, de la época de Carlos III (17591788), con sus hojas de pergamino, escritas a mano, en letra de no difícil lectura para el profano, a excepción de ciertas caprichosas y enrevesadas abreviaturas, entonces muy usadas, pero mudables y no sujetas a regla fija alguna; sus páginas aparecen orladas con dibujos a pluma, complicadísimos en las más antiguas y algo sencillos en las más modernas -ya que, como diremos, las había de diferentes tiempos- y con las rúbricas, también generalmente complicadas y trabajosas, de los que autorizaban y legalizaban la Carta. Pendiente en hilos de seda, de colores y trenzados, lleva el pesado sello de plomo (un kilogramo aproximadamente) del mismo Rey Carlos III; es de un gran valor histórico y contiene, aparte de los dibujos citados, sellos reales en tinta y cera, pinturas, firmas de. Monarcas y dignatarios, etc.; destacando, como verdaderas joyas, el retrato, pintado en colores, de Carlos II y el escudo de armas, igualmente pintado, de la ciudad de Alhama.

Se acostumbraba por aquel entonces a que las Cartas de 
Privilegios, otorgadas por un Rey y para continuar en su vaidez, fuesen confirmadas por todos los que le sucedian, de tal guisa, que era éste requisito necesario e indispensable, por lo que solicitada la confirmación de una de ellas, si no lo estaba al menos por los tres Monarcas inmediatos anteriores a! reinante, dicha confirmación había de ser negada; si bien, a veces, era expresamente dispensada la dicha condición; el propio Carlos III, en su Real Cédula de 15 de enero de 1760 , así lo dispuso.

La Carta de Alhama, como fué otorgada por los Reyjes Católicos, necesitaba la confirmación de Carlos I (1517-15̃56), Felipe II (1556-1598), Felipe III (1598-1621), Felipe IV (16211665), Carlos II (1665-1700), Felipe V (1700-1746) y Fernando VI (1746-1759); solicitada, pues, la confirmación de Carlos III, era absolutamente imprescindible la de sus tres inmediatos antecesores, mas como sólo lo estaba por Felipe III, Carlos II y Felipe V, procedía su denegación. Pero ese Soberano remite especialmente la condición y la confianza "sin embargo de lo dispuesto por otra nuestra Cédula... en que prevenimos no se librase Confirmación alguna de ningun Privilegio, que no lo estuviese de los tres ultimos Señores Reyes nuestros predecessores".

También era acostumbrado en el momento de la confirmación de una Carta de Privilegios, el transcribir. íntegramente el texto de la anterior, con lo que el trabajo era mayor y pródigo en extensas repeticiones, mas el nombrado Carlos III, en otra Real Cédula de igual fecha, 15 de enero de 1760 , reiteró la orden de que en lo sucesivo y salvo petición en contra de la parte interesada, sólo se pusiese en las confirmaciones que se expidiesen, la cabeza y el pie, uniéndose la anterior "de manera que el pliego, o plieg. ${ }^{3}$ de la referida cabeza y pie de Confirmaciō vengan al justo y plana rengion en quanto ser pueda con la otra escritura de los Privilegios que se confirmaren. quitando dei Privilegio el sello que tubiere porque se han sellar de nuevo, como mas adelante irá declarado, y rubricareis y señalareis al principio el pliego de la tal Confirmaciō y de' Privilegio antiguo, por que en ello no pueda haver fraude: 
$\mathrm{Y}$ porque podia ser que algunas de las partes, no embargante... quisieren que sus Privilegios se escriviesen a la letra, mando que se haga assi, quando las dichas partes lo pidieren". Así se observa, que en la Carta de que hablamos, Carlos III sólo pone pie y cabeza a su confirmación, como asimismo hizo Felipe $\mathrm{V}$, pero Carlos II copió integramente la de los Reyes Católicos.

Como dijimos, la concesión de la Carta de Privilegios de Alhama, lo fué en tiempo del primer Conde de Tendilla, el cual entró en esa población, para defenderla de los moros, en el año 1483, después de su toma por Fernando e Isabel; estos Monarcas ofrecieron al Conde clar a dicha ciudad cinco lugares de su jurisdicción: Cacin, Fornes, Jayena, Arenas y Jatar - Ayuntamientos independientes en la actualidad- el mismo privilegio que ya tenían concedido las de Antequera y Teuahardales (hoy Teba y Ardales, Municipios de la provincia de Málaga) y la villa de Tarifa.

Como consecuencia de ello, don Iñigo López de Mendoza solicitó de los Reyes otorgasen la Carta prometida, los cuales se sirvieron concederla en la ciudad de Tarazona el día 22 de marzo de 1484. En ella "Por contemplaçion de el dicho Conde e acatando los grandes 'e mui señalados Seruiçios, que d: el hauemos rreçiuidos, e cada dia rreçiuimos; ansí en la de. fensa de la dicha Çiudad de Alhama, como en la guerra que de ella ha fecho e façe a los Moros enemigos de Nuestra Sancta Fee Catholica, e entendiendo que cumple ansi a nuestro Seruiçio, e a la Guarda, e defensa de la dicha Çiudad de Alhaman y "Por quanto segun el Lugar donde la dicha Çiudad esta situada y el gran peligro y afrenta que rreçiuen los que en ella estan para la defender, con estas e mayores merçedes, mereçen ser rremunerados", se conceden a Alhama y lugares de su jurisdicción, las siguientes "honrras, merçedes y franquezas y libertades y essempçiones, preheminençias y prerrogativas", que después examinaremos:

a) Que a todos los que a sus costas sirvieren en el ejército del Conde, en la ciudad, durante ocho meses, fueren perdonados de cualquier muerte o muertes, homicidios y malefi- 
cios criminales que hubieren cometido o cometiesen; salvo el traidor o alevoso que entregare castillo, matase a su señor o quebrantare tregua. Los que guarnecian castillos fronterizos habían de servir, para gozar del privilegio, durante un año y un día.

b) Que sus vecinos y moradores no pagasen diezmo, portazgo, veintena ni alcabala por sus entradas y salidas de mercaderías.

c) Que si algunos de los que hacían correrías por tierras enemigas, apresaran y trajeran a la ciudad moros $u$ otrcs contrarios, no tuviesen que dar quinto, ni otro derecho alguno, al hacer la almoneda.

d) Que ningún mercader que llevase a la ciudad mantenimientos o armas, hubiere de pagar derecho alguno.

e) Que los vecinos y moradores de la ciudad y sus lugares pudieran hacer en sus casas hornos para cocer pan, cal, tejas y ladrillos, sin abonar ninguna clase de derecho, y

f) Que pudieren tener, Alhama y lugares, sus terminos, con montes, pastos y aguas "bien e cumplidamen'te".

Cuyos privilegios eran mandados observar y respetar de la manera más amplia y terminante, ordenándose expresamente que no prevaleciera en su contra ningún juicio que pudiera tramitarse, ni acusación, ni sentencia, en fin, pues así lo "mandamos e queremos e tenemos por bien) (expresión precisa de la célebre'real gana) y no obstante lo que pudiera estar previsto en cualquier ley, ordenanza, pragmática o sanción; disponiendo dichos Monarcas, al propio tiempo, que aquellos de cualquier clase o condición que hicieren algo en contra de los. citados privilegios, fuesen privados de los oficios o cargos que desempeñaren y castigados también con la confiscación de sus bienes.

Examinando los expresados privilegios, vemos cómo en el primeramente nombrado, los Reyes, como dueños y señores entonces de la vida y hacienda de sus súbditos, disponen libremente de ellas y todo lo subordinan al fin primordial de la obra de la Reconquista; hasta tal punto, que perdonan a los que contribuyen a ella con las armas, de cualquier crimen que 
hayan cometido o puedan cometer (verdadera monstruosidad) $e$ incluso los llamados "malefiçios criminales", que eran los delitos contra la Santa Religión y la $\mathrm{Fe}$, de las que, por otra parte, fueron tan celosos defensores. Se deduce también de su contexto, una primera muestra de la debilidad económica de la época, ya que establecía la condición de que los "omiçianos" sirviesen los ocho o doce meses, a "sus propias costas y missiones".

$\mathrm{Y}$ solamente se exceptúan de tal amplio perdón aquellos ca sos que, directa o indirectamente, pudieran ocasionar perjuicio a la causa de la Reconquista, aparte de la consideración deshonrosa de los delitos mencionados, que herían profundamente el alto concepto que del honor se tenía en la Edad Media.

Los diferentes tributos de que trata el apartado $b$ ) de los privilegios enumerados, corresponden a aquella época en que las Haciendas públicas tenían poca preparación y medios pa ra establecerlos y cobrarlos, siendo algunos de ellos derechos primitivamente feudales y que después se transfieren a la Hacienda real.

Por lo general, la aparición y desarrollo de las Haciendas públicas camina de abajo a arriba, o sea, que empiezan en las municipalidades en un ámbito reducido, hasta llegar a la Hacienda estatal, y así sucede en España, donde tenemos que las primeras bases de imposición las encontramos en los recursos de las Haciendas de los pueblos, que atienden con ellos al sostenimiento de sus propias cargas y contribuycn, además, a las del Estado. Ahora bien, cuando éste adquiere la necesaria pujanza y constituyen su unidad, los términos se invierten, y si antes la Hacienda estatal se nutría casi exclusivamente de las locales, cuando la centralización se establece son éstas las que dependen de aquélla, en mayor o menor grado.

Los tributos mencionados cumplen su misión en el referido proceso, y brevemente expuestos eran: diczmo, derecho de! diez por ciento, que se pagaba al Rey, del valor de las mercaderías que entraban o salían de la localidad; portazgo, derecho que se pagaba por pasar por un determinads 
lugar de un camino o una puerta o entrada, siendo, en parte, el equivalenie al aimojarifazgo de los árabes, sobre importación y exportación, en zonas fronterizas; veintena, derecho que tenía el poseedor de un censo perpetuo para cobrar la vigésima parie (o cinco por ciento) de su valor, siempre que se rendía la cosa objeto de la carga; alcabala, impuesto que gravaba la circulación de las mercaderías al ser vendidas o permutadas y recaía sobre su precio o valor, habiendo sido tomada también de los árabes por las Monarquías cristianas en la Reconquista y siendo sistemáticamente regulado en la Ley once y siguientes del Título XII del Libro X de la Novisima Recopilación. Etimológicamente, se deriva del árabe al-gabala, cobranza, recepción, de donde viene nuestra expresión popular de gabela, para designar cualquier clase de gravamen o carga.

El tributo del quinto, después mencionado, consistía en el derecho que se pagaba al Monarca de las presas, tesoros y cosas semejantes, en la cuantía de la quinta parte de lo aprehendido, hallado o descubierto, según su valor y en sus casos, del precio obtenido de su venta en pública subasta o almoneda.

En cuanto al apartado $e$ ) siguiente, hemos de exponer que en aquel tiempo era privilegio de algunos señores o real, el ser los únicos que, en los pueblos que les estaban sometidos, podían construir y usar hornos, sobre todo de pan, si bien mediante el pago de un canon o derecho permitían a veces que otros pudiesen realizarlo.

Todos aquellos derechos y tributos eran expresamente remitidos, en la Carta de Privilegios, a los vecinos y moradores de Alhama y lugares de su jurisdicción.

Por último, se habla en la misma del privilegio de tener sus montes, con árboles, pastos y aguas, como estaba cen tiempo que era de los morosn; esto hace suponer que, por necesidades guerreras seguramente, fueron talados o devastados y qu: serían repoblados en lo menester.

En un principio, la arboleda era frondosa y abundaban los. bosques en la Península, mas pronto las exigencias de las construcciones navales, de la edificación, del combustible, etc., ha- 
cen que vayan desapareciendo, tan rápida y lamentablemente, que ya en la Edad Media se ocupan los Reyes de la defensa y custodia de los montes, como es de ver en el Fuero Juzgo: En el de Nájera se dictan las primeras medidas de su policía; las Cortes de Valladolid de 1256 y 1351 piden remedios contra las devastaciones que padecían y los Reyes Católicos, en las de Coledo de 1480, dictaron una pragmática, a fin de restituir a los pueblos los montes, prados, pasios y aguas que le habían sido usurpados por concejos, caballeros y otras personas; desde entonces hasta casi nuestros días no cesa la constante desaparición del arbolado y las muchas veces inútiles medidas para protegerlos y realizar su repoblación. En el año 1863 se llega ya a una seria ordenación y hoy se presta al asunto el debido respeto y atención.

Históricamente, se supone, primero, que los montes eran dominio inminente de la Corona (principio de la regalía); después, el Estado, por el interés público que los mismos ofrecen, se conceptúa dueño de ellos y dicta normas para su adecuada utilización; y por último, se admite la coexistencia de los de propiedad particular, si bien el Gobierno se reserva el velar por su conservación, ejerciendo la oportuna vigilancia.

Tal es el contenido esencial de la Carta de Privilegios, que después de otorgada es respetada y observada en todas sus partes; mas pronto, la penuria del Tesoro público, que antes indicamos, hace mella en aquella parte que se refiere a la economía y vemos que en 1615, en tiempos de Felipe III, y an'tes de conceder su confirmación a la misma (tal vez a pretexto de que no lo estaba), el Fiscal de la Real Hacienda demanda a la ciudad de Alhama, pretendiendo que sus vecinos pagasen alcabala en todo lo que no fueren productos de su labranza y crianza, no obstante lo que concretamente se prevenía en la Carta y fundándose en el precepto general de que todos los habitantes del reino debían pagarla, a excepción de lo mencionado y siempre que para ello tuviesen privilegio particular.

Comparecido el Concejo, Justicia y Regimiento de dicha ciudad y cinco lugares de su jurisdicción, por medio del capitán don Juan de Peralta, vecino y Regidor de la misma, se 
termina el pleito mediante transacción, concertándose el pago de dichas alcabalas (aunque no muy gustosamente) en $\mathbf{1 1 8 . 6 8 8}$ maravedises anuales, sin que pudiera cobrarse ninguna otra "para isiempre jamás". Debiéndose, además, de pagar otros $300.000 \mathrm{mrs}$. por sus tercias - no contenidas en la Carta de Privilegios y que consistían en los dos novenos de todos los frutos, rentas y demás productos que integraban los diezmos eclesiásticos, que fueron concedidos a los Reyes, primero para mantener la guerra contra los infieles y después para las demás atenciones de la Corona; y recabados a perpetuidad por los Reyes Católicos, fueron así concedidos por el Papa Alejandro VI, en su Bula de 1494-, mas "por la merçed qua Su Magestad haçe a la dicha Ciudad en lo suso dicho, le haya de seruir y sirua con veinte mill ducados". Seguramente que los vecinos de Alhama jurarían no haberse dado cuenta de la merced.

Para la obtención de cuyos ducados se le permite tomarlos, en todo o en parte, a censo sobre sus bienes propios, rentas y dehesas; autorizándose asimismo a la ciudad, para el pago de réditos y redención de censos, a arrendar una dehesa boyal de su término y si alguna cantidad faltare aún, podría repartirla entre sus vecinos, según su hacienda, a vía de empréstito y "no haçiendo agrauio a nadie». Decretándose también que los ingresos así obtenidos, habrían de tener contabilidad y caja aparte de la general de la municipalidad. ¿Verdad que parece que estamos leyendo disposiciones de actualidad?

Vemos que, como anteriormente reflejamos, la facultad real era tan amplia y absorbente, que regulaba expresamente 'a creación y administración de un impuesto local, y por otra parte esto mismo nos corrobora la marcha general del proceso histórico impositivo, pues en ese su finalidad exclusiva era la de cubrir atenciones de carácter nacional.

Quedando así el pleito terminado, se ordena en consecuencia por el Soberano que "no se pueda seguir aora, ni en tiempo alguno, ni sobre lo mismo se pueda mouer otro y sobre la forma y carga con que ha de tener la franqueza de essempçion de alcauala y las demas cossas contenidas en el dicho assiento 
como mas particular mente en el se declara por la pressente lo aprueuo y rratifico y prometo asseguro por mi palabra rea', que guardandose y cumpliendose por la dicha Çiudad, lo que por el esta obligada se guardara y cumplira y mando se guarde y cumpla de la mia lo que me toca sin faltar ni exçeder de ello cosa alguna".

A pesar de todas esas promesas y seguridades, muerto el que las hizo y durante el reinado de Carlos II, en el año 1680, el Fiscal de la Real Hacienda, de nuevo y con igual motivación, demanda a la ciudad para que no use más de sus privilegios y pague alcabala por los productos de su cosecha, "labranza y crianzan; sucede entonces lo que todavía es algo frecuente en ias Corporaciones locales, que desidiosamente se dejan transcurrir los plazos hábiles de comparecencia y es condenada en rebeldía. Acude entonces la ciudad al Monarca alegando sus maltratados privilegios y la transacción anteriormente pactada, pidiéndole que fuesen respetados, que se impusiere "perpetuo silencion a los Fiscales sobre el particular y ofreciendo servir a su Majestad con tres mil ducados. Al mismo tiempo se solicitaba la necesaria autorización para establecer arbitrios sobre el jabón, aceite y lana y el arriendo de los pastos de sus montes, para con ello conseguir los 3.000 ducados y las costas del pleito.

Es denegada la petición de la ciudad; en vista del "corto ofreçimiento que haçian (se conoce que, en aquellos tiempos, estas cosas se arreglaban numéricamente) por lo que se produce un nuevo of recimiento, esta vez de 60.000 reales de vellón -sobre el doble del anterior-y solicitó, además, el Cabildo, que se le permitiera cortar y entresacar los árboles infructíferos de sus dehesas de Jatar y Sierra Tejeda y vender las leñas resultantes para allegar recursos.

Se acepta ya el ofrecimiento, reconociendo y confirmando el Monarca el privilegio (ya mermado por la anterior transacción) y denegando la implantación de los arbitrios, a excepción del propuesto de corta de árboles - garantizando su señalamiento con la presencia del Corregidor de la ciudad-, pero afectando directamente su rendimiento al pago de los 60.000 
reales y costas del pleito, debiendo llevarse caja y contabilidad por separado.

Con el transcurso del tiempo, conforme se iba robusteciendo la autoridad real y centralizándose el poder, los privilegios van languideciendo, corriendo igual suerte que los Fueros y Cartas-pueblas, que sirvieron a los Reyes en un principio para su afianzamiento y que, luego, al convertirse en estorbos, son suprimidos más o menos violentamente.

Así mueren los de Alhama y después que nadie se ocupa ya de alegarlos, tal vez porque sabían que no habían de ser atendidos y ante la impetuosa corriente de centralización legalista en el aspecto municipal.

Salvador Cañas Gómez

Secretario de Administración Local de $1 .^{a}$ categoria 